\title{
IN NATURA VERITAS: EL SISMO DE 1985 Y LA FUNDACIÓN PARA EL APOYO DE LA COMUNIDAD
}

\author{
Andrea Mutolo*
}

RESUMEN: Este artículo analiza el papel que desempeñó el Arzobispado de México en la reconstrucción de la Ciudad de México, después del sismo de 1985. La diócesis fundó ex novo una institución llamada Fundación para el Apoyo de la Comunidad (FAC), con la tarea específica de encargarse de la reconstrucción. Rápidamente, la FAC se trasformó en uno de las organismos no gubernamentales más dinámicos y grandes en el proceso que vivió la ciudad después del sismo. Todo esto generó una cercanía con los gobiernos locales (las delegaciones y sobre todo el Departamento del Distrito Federal) y también con el gobierno federal, en un contexto en el que las relaciones entre Estado-Iglesia católica no se habían formalizado.

PALABRAS ClAVE: Arzobispado de México, sismo de 1985, Iglesia católica, Ciudad de México.

RECEPCIÓN: 19 de mayo de 2016.

ACEPTACIÓN: 22 de septiembre de 2016.
IN NATURA VERITAS: THE 1985 EARTHQUAKE AND THE FOUNDATION FOR COMMUNITY SUPPORT

ABSTRACT: This article discusses the role played by the Archdiocese of Mexico in the reconstruction of Mexico City after the earthquake of 1985 . The diocese founded an institution called the Foundation for Community Support with the specific task of rebuilding. It quickly became one of the most dynamic and largest non-governmental organizations during the process of reconstruction after the earthquake. All this generated a close proximity with local governments (the different boroughs and especially the Mexico City government) and also with the federal government, in a context where relations between the State and the Catholic Church had not been formalized.

KEYWORDS: Archdiocese of Mexico, 1985 earthquake, Catholic Church, Mexico City.

* Profesor investigador de tiempo completo en la Academia de Historia y Sociedad Contemporánea de la Universidad Autónoma de la Ciudad de México. Doctor en Historia Eclesiástica por la Pontificia Universidad Gregoriana, Roma. 


\section{IN NATURA VERITAS: EL SISMO DE 1985 Y LA FUNDACIÓN PARA EL APOYO DE LA COMUNIDAD}

\section{Introducción}

El papel de la Iglesia católica cambió en el sismo del 19 de septiembre de 1985 en la Ciudad de México. Creo que la máxima latina in natura veritas conviene para este caso: un fenómeno natural removió la estructura social y política de la ciudad para llegar a la esencia antropológica del hombre. En el caso de la Iglesia católica, por primera vez se dejaron a un lado conflictos históricos que caracterizaron el siglo XX mexicano, y gobierno e Iglesia confluyeron en un proyecto común.

Este artículo se enfoca en la historia de la Fundación para el Apoyo de la Comunidad (FAC), una organización no gubernamental del Arzo- bispado de México, muy activa en la reconstrucción de la Ciudad de México después del sismo de 1985. Analizo los orígenes de esta institución inmediatamente después del terremoto, su desarrollo y su cierre en 1995, terminada totalmente la etapa de reconstrucción. FAC se convirtió rápidamente en una de las instituciones más sobresalientes e importantes para la reconstrucción de la ciudad.

He utilizado como fuentes primarias las entrevistas realizadas a los principales participantes, libros y folletos (muchos editados por la FAC), periódicos y revistas ( $L^{\prime}$ Osservatore Romano, La Gaceta Oficial del Arzobispado, Proceso), y he revisado el Fondo Base Cancillería del Archivo Histórico del Arzobispado de México. 
Para los antecedentes bibliográficos es importante aclarar que no hay referencias directas sobre el papel de la Iglesia católica en el trabajo de reconstrucción después del sismo de 1985. Con respecto a la sociedad civil y el terremoto hay una bibliografía limitada, pero que constituye un corpus importante. Sobre el terremoto se cuenta con una extensa bibliografía de memorias, documentales, artículos de prensa, aunque pocos estudios científicos que analicen este fenómeno y menos los dedicados al papel de la ciudadanía. Este estudio es el primero en el que se analiza el desempeño de organizaciones relacionadas con la Iglesia católica.

El sobresaliente papel de los capitalinos en el terremoto de 1985 aparece en varios trabajos, como los de dos intelectuales muy reconocidos en México, Carlos Monsiváis ${ }^{1}$ y Elena Poniatowska, ${ }^{2}$ que subrayan el despertar de la sociedad civil capitalina, la cual reacciona y se organiza para enfrentar la emergencia y luego pasa a la etapa de reconstrucción. La tesis principal de esas obras es que, en la reconstrucción, no se puede confiar en el gobierno. La misma ciudadanía considera que, lo mismo el gobierno federal que el Departamento Distrito Federal, son ineficientes y corruptos.

\footnotetext{
${ }^{1}$ Carlos Monsiváis, No sin nosotros. Los días del terremoto, 1985-2005, 2005, México, Era.

${ }^{2}$ Elena Poniatowska, Nada nadie. Las voces del temblor, 1988, México, Era.
}

Por esta causa, la sociedad civil fue el actor principal que tomó las medidas para que la Ciudad de México se levantara y la que inició el enorme trabajo de reconstrucción.

Nuestro objetivo es contribuir por medio del estudio de un actor específico a este complejo debate vinculado al papel de la sociedad civil en el sismo de 1985. A diferencia de otros actores más críticos, la FAC fue una institución muy cercana y colaboradora con el gobierno.

¿Cuál es la relevancia de FAC en este proceso? Entre 1986 y 1994, la FAC construyó o remodeló más de 8,000 viviendas. ${ }^{3}$ Pero además, nuestra hipótesis es que la FAC fue relevante porque trajo una apertura de la Iglesia católica hacia la sociedad civil y hacia el Estado. Una novedad de todo esto está en el hecho de que una institución abiertamente controlada por la jerarquía establezca formalmente un vínculo estricto y formal con el gobierno. Como explica Roderic $\mathrm{Ai}$ Camp, en muchos casos las relaciones entre Iglesia católica y el Estado fueron excelentes también en la década de 1970, pero estaban a cargo de intermediarios y prestanombres. ${ }^{4}$

${ }^{3}$ Según datos de la FAC, el total de viviendas construidas, remodeladas o que recibieron apoyo económico de la institución fue de 8570 unidades entre 1986 y 1994. José Antonio Ibáñez Aguirre, FAC, 1985-1995, 1995, México, Fundación para el Apoyo de la Comunidad, p. 49.

${ }^{4}$ Roderic Ai Camp, Cruce de espadas. Politica y religión en México, 1998, México, Siglo XXI, p. 322 . 
Es evidente que en este cambio participaron muchos elementos, pues la FAC, con ser una pieza relevante, no fue la única. Otros elementos tuvieron su parte, aunque no quepa analizarlos en este texto porque escapan nuestro objetivo. Pienso en el papel de Girolamo Prigione ${ }^{5}$ en el sexenio salinista o incluso en las modificaciones y ajustes que se produjeron como consecuencia del Concilio Vaticano II y de la II y III CELAM.

La fundación y el desarrollo de la FAC coincide con una trasformación impulsada por el cardenal Ernesto Corripio Ahumada. ${ }^{6}$ En alguna forma, la FAC es parte de un amplio proyecto de renovación que se produce en la década de 1980 en el catolicismo de la Ciudad de México.

${ }^{5}$ Girolamo Prigione nació en Castellazzo Bormida (Italia) en 1921. En 1944 fue ordenado sacerdote diocesano y a continuación entró en la Academia Eclesiástica Pontificia, que es la escuela que forma a los diplomáticos de la Santa Sede. A los 46 años fue elegido nuncio apostólico en El Salvador y Guatemala. En 1973 fue trasladado a Nigeria, donde permaneció hasta 1978, cuando vino a México. Girolamo Prigione fue delegado apostólico hasta el restablecimiento de las relaciones diplomáticas entre México y el Vaticano en 1992. Una vez formalizadas estas relaciones, fue nuncio apostólico hasta su jubilación en 1997.

${ }^{6}$ El cardenal Corripio dirigió la Arquidiócesis Primada de México entre 1977 y 1994. En 1979 Juan Pablo II lo nombró presidente conjunto de la III Conferencia Episcopal de América Latina (CELAM) en Puebla. Encabezó la diócesis hasta que cumplió la edad canóniga para jubilarse, en 1994. Murió en 2008.

\section{El arzobispado de México en la década de $\mathbf{1 9 8 0}$}

El análisis que hace Roberto Blancarte de la presidencia de Corripio en la Conferencia Episcopal Mexicana en 1980-1982 revela una apertura de la Iglesia en las cuestiones sociopolíticas. ${ }^{7}$ Esta apertura se evidencia también en el gobierno de la diócesis. Las reformas impulsadas no se dirigieron exclusivamente a una apertura en la relación de la Iglesia católica con el Estado, sino a un cambio interno muy significativo. Probablemente la evolución más reveladora haya sido la reconfiguración territorial del arzobispado. Con la llegada de Corripio al Arzobispado de México, se investigó y se determinó que la estructura pastoral de la diócesis tenía que cambiar y transformarse para responder a las nuevas necesidades de una megalópolis.

En las zonas de pastoral de la arquidiócesis (a las que se le llamó después "delegaciones de pastoral") ya había trabajo realizado durante la gestión del cardenal Miguel Darío Miranda y Gómez (arzobispo de México de 1956 a 1977). En 1977, Corripio quiso avanzar y dio personalidad jurídica a estas zonas pastorales, que no tenían un obispo encargado, sino

\footnotetext{
${ }^{7}$ Roberto Blancarte, Historia de la Iglesia católica en México, 1992, México, FCE-Colmex, p. 409.
} 
delegados. ${ }^{8}$ Ahora bien, no era únicamente un problema jurídico, sino que había que entender el fenómeno de la gran ciudad, los problemas pastorales, la conveniencia de nombrar obispos y, si se nombraban, cómo tenían que ser reglamentados.

El análisis del sacerdote diocesano Manuel Zubillaga, ${ }^{9}$ encargado de reestructurar la diócesis, se centra en las ciencias sociales y toma como marco de referencia las megalópolis. En la década de 1980, estas ciudades de más de ocho millones de habitantes eran veinticuatro o veinticinco, y se trataba ya de un fenómeno del siglo XX, porque, por ejemplo, a finales del XIX apenas Londres tenía un millón de habitantes. Por ser algo tan reciente, también era un asunto nuevo para la Iglesia. La concepción canónica de diócesis comenzó a tener un sustrato sociológico diferente, que llegó a ser punto de partida. Fue necesario inventar, literalmente, una solución de gobierno pastoral de una megalópolis.

En la década de 1980, la diócesis revolucionó su división canónicaadministrativa y se dividió en ocho

${ }^{8}$ Comunicación verbal de Manuel Zubillaga, México, 14 de junio de 2009.

${ }^{9}$ Manuel Zubillaga nació en la Ciudad de México el 5 de junio de 1947. Es sacerdote diocesano del Arzobispado de México. Fue presidente de Caritas diocesana de la Ciudad de México en la década de 1990 y en la primera década del siglo XXI. vicarías, las cuales se fraccionaron en decanatos y estos en parroquias. Ya establecida la nueva división, empezaron los cambios concretos. Los primeros obispos elegidos como administradores de una vicaria fueron Francisco Aguilera González y Javier Lozano Barragán, elegidos en junio de 1979.

\section{Los orígenes de la FAC}

La creación de la FAC después del sismo de 1985 fue parte de los cambios que impulsó el cardenal Corripio desde su llegada a la diócesis. En cierto sentido, la FAC es parte del esfuerzo para modernizar la diócesis y darle una estructura más incluyente y conforme con la nueva situación política y social de la Ciudad de México. ${ }^{10} \mathrm{Si}$ queremos comprender el surgimiento de la FAC, hay que considerar que representó y, en alguna forma, reagrupó la acción social del Arzobispado de México.

En la década de 1980, al igual que en nuestros días, el instrumento que las diócesis utilizaban para el desarrollo de la pastoral social era Caritas, pero en el caso específico de la Ciudad de México, la Caritas

\footnotetext{
${ }^{10}$ Roderic Ai Camp aclara que en el sexenio de Miguel de la Madrid (1982-1988), Corripio hizo un esfuerzo para acercarse al gobierno; véase $o p$. cit., p. 333 .
} 
diocesana, ${ }^{11}$ fundada en la parroquia de San Miguel de Tacubaya en 1960, y que quedó demasiado vinculada a contextos parroquiales que limitaban la acción.

Así se desencadena una problemática vinculada a la Conferencia Episcopal Mexicana (CEM), en particular a la Comisión Episcopal de Pastoral Social (CEPS), que con sus vínculos burocráticos y su trabajo colegial — según el punto de vista del Arzobispado-, podía debilitar la fuerza y la contundencia de una institución que actuaba en un contexto de absoluta emergencia. Por esta causa, se tomó la decisión de crear la FAC como organización, en diciembre de 1985. De esta forma, el Arzobispado pudo ejercer el control absoluto sobre la nueva institución (y los muchos donativos), al tiempo que la nueva estructura pudo actuar en forma rápida y flexible.

El fundador y luego director del FAC fue el sacerdote jesuita Enrique González Torres, ${ }^{12}$ que había sido

${ }^{11}$ En la I CELAM de 1955 en Rio de Janeiro, se llegó al acuerdo de fundar las primeras Caritas diocesanas en América Latina. En la región había comisiones de pastoral social y secretariados, pero no las Caritas. En este contexto, la Caritas diocesana de la Ciudad de México se constituyó en 1960. En un principio, su visión era muy interesante, pues realizó un trabajo de cooperativas vinculadas al concepto educativo formativo, y no solo al enfoque asistencial.

${ }^{12}$ Enrique González Torres nació en la Ciudad de México en 1940. Se ordenó jesuita en 1970. Tiene una maestría en educación por la Universidad de secretario ejecutivo de la Comisión de Pastoral Social, estructura vinculada a la CEM: "Yo no trabajaba a gusto en la comisión de Pastoral Social, porque los veía lentos [...] además había gente que llegaba ofreciendo aportaciones, tanto en alimentos, en dinero o cobijas. Yo sugerí que hiciéramos un fondo de ayuda católico, para ir canalizando los recursos". ${ }^{13}$

La forma de actuar de González, que para algunos resultaba demasiado autónoma, empezó a causar problemas con el presidente de la CEPS Carlos Talavera. ${ }^{14}$ Cuando González Torres dejó la CEPS, se generó una enorme tensión entre la CEPS y la diócesis, a mi parecer, por el control de los donativos. En efecto, si se consulta la Gaceta Oficial del Arzobispado de México, el número siguiente al sismo de 1985, se habla de un Fondo de Ayuda Católica (FAC) y de como la "CEPS, presidida por Mons. Carlos Talavera, Obispo de Coatzacoalcos,

Stanford, California. De 1976 a 1983 fue director del Centro de Estudios Educativos. Más adelante creó y dirigió la FAC de 1985 a 1995 . Fue rector de la Universidad Iberoamericana, Ciudad de México, de 1996 a 2004.

${ }^{13}$ Entrevista con Enrique González Torres, Ciudad de México, 26 de agosto de 2015.

${ }^{14}$ Carlos Talavera Ramírez (1923-2006). Fue ordenado sacerdote diocesano en el Arzobispado de México en 1948 y consagrado obispo en 1980. Entre 1980 y 1984 fue obispo auxiliar de la Ciudad de México y entre 1984 y 2002 fue el primer obispo de Coatzacoalcos. Murió el 2 de julio de 2006. 
tiene a su cargo la coordinación del Fondo de Ayuda Católica". ${ }^{15}$

El cardenal Corripio respaldó la propuesta de González Torres de crear una fundación, si bien se cambió el nombre del Fondo de Ayuda Católica de la CEM por el de Fundación para el Apoyo a la Comunidad, conservando la sigla FAC, que era imperativo hacer. El Fondo de Ayuda Católica controlado por la Comisión de Pastoral Social prácticamente desapareció. Por esta razón, en los números de 1986 en adelante de la Gaceta Oficial del Arzobispado desapareció la FAC como Fondo de Ayuda Católica, sustituida por la FAC como Fundación para el apoyo de la Comunidad: "La Arquidiócesis de la Ciudad de México decidió crear la FAC para que fungiera en una primera etapa, como el organismo ejecutor de las acciones emergentes de Pastoral Social en favor de nuestros hermanos que resultaron afectados por los fenómenos naturales de septiembre de 1985". ${ }^{16}$

Otro punto de conflicto en el momento de la fundación, que se alargó durante la historia de FAC, fue la relación controvertida entre la fundación y la provincia mexicana de los jesuitas. La fundación surgió en un periodo

${ }^{15}$ Gaceta Oficial del Arzobispado de México, "La Iglesia unida a sus hermanos", segundo semestre de 1985, pp. 52-53.

${ }^{16}$ Gaceta Oficial del Arzobispado de México, "El papel de la Fundación para el Apoyo de la Comunidad, A.C. (FAC)”, abril-junio de 1987, p. 61. sumamente difícil para la provincia. En la década de 1980, los conflictos personales se sumaron a las dificultades de los tiempos. Los religiosos, con la supervisión del prepósito general de la Compañía, Pedro Arrupe, tomaron un camino diferente.

Enrique González Torres no logró atraer al proyecto diocesano a su provincia. El provincial Carlos Vigil ${ }^{17} \mathrm{y}$ un sector de los jesuitas mexicanos se mostraron escépticos y críticos. De hecho, los jesuitas vinculados aAcción Popular ${ }^{18}$ se mostraron desconfiados de la FAC, sobre todo por su apertura a un proyecto común con el gobierno. Entre tanto, la postura de González Torres era más pragmática. No consideraba al gobierno intrínsecamente corrupto o malo, y la FAC se convirtió en una institución adecuada para

${ }^{17}$ Carlos Vigil. Nació en 1934. Fue ordenado sacerdote jesuita en 1966. Provincial en México de 1983 a 1989. Luego fue rector de la Universidad Iberoamericana, Ciudad de México, de 1992 a 1996 y director de Buena Prensa de 2005 a 2009.

${ }^{18}$ Acción Popular es una corriente interna a la provincia de los jesuitas en México surgida a comienzos de la década de 1970, con el cierre del Instituto Patria en la Ciudad de México. Apoyó incondicionalmente a la Congregación General 32 y la Carta de Río. El provincial Enrique Gutiérrez Martín del Campo, siguiendo las políticas de padre Arrupe, había tomado la controvertida decisión de cerrar el instituto y se generaron graves problemas. En su momento, González Torres apoyó el cierre del Patria y participó en las asambleas de Acción Popular, pero en las entrevistas se observa un distanciamiento $\mathrm{y}$ un conflicto entre los jesuitas que pertenecieron a esta corriente y la constitución y desarrollo de la FAC. 
colaborar con el Estado en proyectos específicos. Todo esto generó problemas personales, al grado de que González Torres dejó temporalmente la comunidad y vivió con sus padres, pues "sentía una agresión muy fuerte".

\section{El papel de la FAC en la reconstrucción de la Ciudad de México}

Con todo, estos conflictos no afectaron el potencial de la FAC, que se consolidó rápidamente y desempeñó un papel importante en la reconstrucción de la ciudad. La principal tarea de la FAC fue la reconstrucción de viviendas, un objetivo complejo en un espacio tan heterogéneo como la Ciudad de México. Por esta razón, aprovechando la estructura de la división del Arzobispado de ocho vicarías, la fundación estableció en 1986 entidades locales, los Centros de Apoyo a la Comunidad (CEPAC).

Gracias a las oficinas de los CEPAC, la FAC pudo diagnosticar las necesidades de cada sector de la ciudad e intervenir en forma heterogénea.

Desde su surgimiento, la FAC se dividió en cuatro áreas:

1. Viviendas

2. Empleo y ocupación

3. Asistencia: salud, nutrición, apoyo económico

4. Swap social

\section{Vivienda}

La estructura parroquial de la diócesis facilitó la evaluación de las necesidades de vivienda. Con la arquitecta Elizabeth García, que colaboraba con la FAC, se desarrollaron proyectos financiados principalmente por muchas Caritas del mundo. ${ }^{19}$ Hubo una enorme disponibilidad económica de parte de la Santa Sede y las Conferencias Episcopales (que controlaban las Caritas nacionales) para financiar los trabajos de reconstrucción. Juan Pablo II hizo varios llamados para apoyar a México: el domingo 22 de septiembre de 1985, se refirió en Génova al sismo: "Deseo, además, estimular toda iniciativa oportuna encaminada a salir al encuentro de las exigencias de ayuda que apelan con urgencia a la solidaridad humana de todos los pueblos y de todas las naciones en un momento tan trágico". ${ }^{20}$

${ }^{19}$ Según lo que declaró la FAC, entre 1985 y 1987, se recibieron 13,566,623 dólares. De este importe, 4,111,070 llegaron de Caritas Italia, 2,798,501 de Caritas Alemania, 2,748,525 de los Catholic Relief Services (Estados Unidos), 1,109,867 de Caritas Suiza, etc. En el mismo periodo, la FAC recibe 3,812,238 de dólares en donativos del extranjero no condicionados (es decir, que no necesariamente tenían que invertirse en viviendas), casi todos procedentes de las diócesis estadounidenses: 536,421 del Arzobispado de Boston, 375,000 de la Arquidiócesis de Chicago, etc. Véase Ibáñez Aguirre, op. cit., pp. 224-225.

${ }^{20}$ L'Osservatore Romano, "Participación del Papa en el dolor por las víctimas de la catástrofe en México", 29 de septiembre 1985, edición semanal, p. 4. 
Entre tanto, el Departamento del Distrito Federal estableció el Programa de Renovación Habitacional Popular en la Ciudad de México, una entidad que se encargó de labores de reconstrucción, en algunos casos con el apoyo de organizaciones no gubernamentales como la FAC o la Cruz Roja Mexicana. Según dijimos, entre 1986 y 1994 la FAC remodeló, construyó y asesoró en la construcción de 8,570 viviendas. Es una cifra elevada, aunque no en demasía. Si retomamos como fecha de corte diciembre de 1987, se observa que la FAC construyó 2,543 viviendas y la Cruz Roja Mexicana 4,414 para la misma fecha. Todas las organizaciones no gubernamentales construyeron 11,660 viviendas. La FAC fue la segunda $\mathrm{ONG}$ en importancia.

Entre 1986 y 1987, el gobierno, con sus varios programas (Renovación Habitacional, Programa Emergente de Viviendas fase I y fase II, Programa de Reconstrucción Democrática de Tlatelolco), construyó 89,703 viviendas..$^{21}$

Las FAC y otras ONG firmaron con el DDF las "Bases para la concertación de acciones suscritas entre el Gobierno Mexicano y diversos organismos y asociaciones civiles nacionales e internacionales, que han aportado

${ }^{21}$ Priscilla Connolly, René Coulomb y Emilio Duhau, Cambiar de casa pero no de barrio: Estudios sobre la reconstrucción habitacional en la ciudad de México, 1991, México, UAM-A, pp. 372-373. recursos para la reconstrucción”. Se trató de una normatividad específica que limitaba los metros cuadrados construibles para viviendas a un máximo de 60 metros cuadrados. Es importante subrayar el hecho de que las viviendas, conforme a la normatividad de las bases de Renovación Habitacional, no se regalaban, sino que se gestionaba con los nuevos dueños un préstamo de intereses bajos. Este vínculo entre la FAC y Renovación Habitacional trajo una cercanía políticamente relevante en las relaciones entre el Estado y la Iglesia católica.

Como vimos, la FAC construyó miles de viviendas gestionando millones de dólares. El vínculo entre la FAC y sus donantes fue en general satisfactorio, salvo en cierto momento en que sobrevino un problema con los Catholic Relief Services, prácticamente la Caritas estadounidense. Sobre este punto, las versiones orales no concuerdan y las fuentes de archivo todavía no son totalmente consultables (los archivos eclesiásticos pueden consultarse hasta 1939; toda la segunda mitad del siglo XX es difícil de consultar). Lo que sabemos es que los CRS se mostraron inconformes por la manera en que la FAC administraba el dinero y construía viviendas. Algunos exjesuitas que participaron en las edificaciones y que residían en la parroquia de Nuestro Señora de Los Ángeles, en la colonia Guerrero, una 
zona céntrica y popular de la Ciudad de México, declararon que el problema entre los CRS y la FAC se debió al hecho de que la FAC inflaba demasiado el valor de las viviendas, por un gasto de gestión muy elevado. "La FAC veía que si nosotros construíamos diez viviendas, ellos construían cinco y quedaban mal."

También se financiaban otras fundaciones, ${ }^{22}$ otras ONG más pequeñas como PASE (Promoción de Actividad Socio Educativa) controlada indirectamente por los jesuitas de la parroquia de Nuestra Señora de los Ángeles, que como se enfocaba el trabajo voluntario y la autoconstrucción, podía reducir sus gastos. La versión de FAC era que la autoconstrucción resultaba imposible si se trataba de erigir 2,000 viviendas, lo que significa contratar profesionales y administrar los gastos. El problema se politizó: González Torres, necesitaba estar informado, pues era el sacerdote encargado de la reconstrucción por parte de la diócesis y su tarea consistía en coordinar la ayuda proveniente de instituciones católicas; pero los CRS, PASE y los jesuitas de la colonia Guerrero se mostraban críticos y no querían informar a la diócesis de sus actividades de reconstrucción. En el Archivo Histórico del Arzobispado

\footnotetext{
${ }^{22}$ Entrevista con Francisco Ramos, Ciudad de México, 20 de enero de 2016.
}

de México se puede examinar un documento de una consultora que revisa los recursos invertidos por la FAC de dinero donado por los CRS. La FAC, por medio del CEPAC cuarto sur, comisionó esta revisión, con la que se aclaró que la Constructora Mont (la empresa a que la FAC encargó la construcción) construyó 271 viviendas y que la FAC recibió donativos de los CRS por un total de $1,673,000$ dólares.

En este informe no hay todavía rastros del conflicto y se concluyó que "las cifras respecto de los costos directos presentados por la Constructora Mont son razonables considerando los parámetros utilizados para las pruebas realizadas". ${ }^{23} \mathrm{El}$ sacerdote coordinador del CEPAC Benjamín Bravo aclaró que "el resultado final, como lo verá, es positivo. Espero que esto genere más recursos para aliviar la necesidad de algunos otros damnificados. [...] Hasta ahora con este dinero de los norteamericanos, ha sido posible construir un buen número de casas, como verá en la misma lista del informe". ${ }^{24}$

${ }^{23}$ Archivo Histórico Arzobispado de México (AHAM), Cancelería, caja 425, Exp. 39, "Gómez Campos Alamilla y CIA, SC (Contadores públicos consultores), Revisión respecto de la aplicación que se dio a las cantidades que le entregó el Organismo denominado Catholic Relief Service", México, $1^{\circ}$ de diciembre de 1987.

${ }^{24}$ AHAM, Cancelería, caja 426, Exp. 23, Carta de Benjamín Bravo a Exmo. Sr. Dr. Dn Luis Mene Arroyo, 11 de diciembre de 1987. 
Empleo y ocupación

En el rubro del empleo, se creó un fondo para apoyar a muchos artesanos que perdieron sus instrumentos de trabajo con el sismo. En particular, se formó un grupo de trabajo llamado los "emprendedores" (en concreto, Fundación los Emprendedores), que se dedicó a rescatar los empleos perdidos. Con el terremoto, un sector laboral vinculado a industrias o zonas que quedan destruidas quedó desocupado, por ejemplo, las costureras de San Antonio Abad. Con el respaldo de algunos empresarios, la FAC estableció mediante la fundación un instrumento para dar crédito a artesanos y ofrecer herramientas de trabajo. Se planearon pequeños proyectos de creación de cooperativas de costura, principalmente en la colonia Roma, que llegaron a sumar veinte, con 414 beneficiarios. $^{25}$

Con el tiempo, el experimento fracasó. Las cooperativas no funcionaron, porque dada su estructura horizontal, era muy difícil llegar a acuerdos funcionales. Según González Torres, las costureras estaban acostumbradas a una estructura vertical, y al formarse las cooperativas tuvieron que ponerse de acuerdo sobre quién era la directora o quién la encargada de ventas, lo que resultó demasiado complejo. p. 69.
Como parte de este rubro, y con el respaldo de Alfredo Hubart, se creó el Centro de Apoyo al Microempresario (Came). La idea era conceder a un promotor la posibilidad de fundar un grupo de diez a veinte personas; en cuatro meses, cada uno ahorraba y solicitaba crédito para emprender alguna actividad productiva. Así se creaba un fondo interno de ahorro, más un fondo de la institución central Came, que podía ser 10 veces mayor que el fondo de ahorro. ${ }^{26}$

\section{Asistencia: salud, nutrición, apoyo económico}

En las ocho vicarías, por medio de los CEPAC se formaron grupos de apoyo no solo para construir viviendas, sino también para favorecer la nutrición, la educación y la seguridad. La FAC había recibido mucho dinero no etiquetado, que destinó activamente a organizaciones de asistencia privada. Se establecieron numerosas instituciones para apoyar a niños con discapacidad, residencias para adultos mayores y para jóvenes con problemas de adicción. Poco a poco, estas iniciativas cobraron vigor. Si en los primeros años los esfuerzos y el presupuesto de la FAC se dirigían principalmente a la reconstrucción y la construcción

\footnotetext{
${ }^{26}$ Entrevista con Enrique González Torres, Ciudad de México, 15 de octubre de 2015.
} 
de viviendas, con el tiempo el capital se dirigió más hacia obras educativas o asistenciales. ${ }^{27}$

En 1988, por necesidades de los donantes (en particular las Caritas europeas), se fundió la prácticamente inexistente Caritas diocesana con la FAC y se creó FAC -Caritas. Todo esto resultó muy importante para el consorcio de las Caritas europeas, porque la FAC adquirió un perfil perfectamente compatible con las instituciones donantes.

\section{Swap social}

El swap es un intercambio que consiste en comprar deuda del gobierno mexicano al 70-80\% de su valor, y el gobierno, por medio de un acuerdo debidamente firmado, queda obligado a monetizar la deuda en su valor nominal (100\%). El dinero generado por estas operaciones financieras se destinó a la construcción de viviendas o la creación de infraestructura nacional. La FAC creó el Faprode (Fondo para la Asistencia, Promoción y Desarrollo), una asociación de segundo piso de intermediación financiera, con el objetivo de comprar deuda gubernamental en el exterior con dinero de los donantes.

\footnotetext{
${ }^{27}$ En la estructura de la FAC, para la promoción social del anciano había dos programas y tres residencias. Ibáñez Aguirre, op. cit., p. 35.
}

Más adelante, la Swiss Bank Corporation financió con un crédito parte estas operaciones. En total, por medio del Faprode se organizaron swaps por 253 millones de dólares. ${ }^{28}$ Todo esto, junto con los programas de viviendas, evidencian la cercanía entre la FAC y diversos niveles de gobierno.

\section{Hacia el cierre}

La FAC dio por concluidas sus labores en 1995, diez años después de su nacimiento: "Pensé que una institución creada con ocasión de un terremoto tiene su inicio y su fin". ${ }^{29}$ Desde 1992 empezó a generarse un cambio en la misma línea de 1988 que trasformó la FAC en FAC-Caritas. En 1992 comenzó un periodo de transición en el cual el sacerdote Manuel Zubillaga se acercó a Enrique González Torres; además, el futuro aparecía incierto y con probabilidad de cambios, considerando que el cardenal Corripio (enfermo en los últimos años) cumpliría la edad canóniga para jubilarse en 1994.

Zubillaga se enfocó más en proyectos formativos y de pastoral social, vinculados a las ocho vicarías y los CEPAC. Es un hecho que el trabajo de construcción de viviendas se estaba agotando, pues los fondos que habían

\footnotetext{
${ }^{28}$ Ibáñez Aguirre, op. cit., p. 177.

${ }^{29}$ Entrevista con Enrique González Torres, Ciudad de México, 26 de agosto de 2015.
} 
financiado el trabajo de la FAC en se terminaban. La transición se caracterizó por una administración dispuesta a modificar el trabajo original de la FAC.

Terminada la etapa de emergencia y de reconstrucción, se volvió a definir la estructura de la FAC: "Lo que hicimos fue crear una Caritas en la Ciudad de México que heredó las cosas de FAC". ${ }^{30}$ Precisamente en 1994 renació Caritas, dirigida por Manuel Zubillaga.

La amplitud del trabajo realizado por FAC estaba pidiendo un paso más en su proceso, desagregarse para dar identidad propia a las acciones realizadas. Por esta razón FAC-Caritas A.C. da lugar a Caritas Arquidiócesis de México, I.A.P., para que el organismo de pastoral social de la Arquidiócesis de México quede plena y específicamente identificado en sus propósitos pastorales y en su alcance referido a la Ciudad de México. ${ }^{31}$

Caritas prácticamente heredó los CEPAC, la parte trabajada y potenciada por Zubillaga con un enfoque de pastoral social, mientras que FACCaritas emprendió entre 1992 y 1994 nuevos proyectos más pastorales y menos empresariales, como las jornadas de caridad y las campañas cuares-

${ }^{30}$ Ibid.

${ }^{31}$ AHAM, Cancillería, caja 228, Exp. 13, Caritas, Arquidiócesis de México, I.A.P, México, 15 de noviembre de 1994, p. 16. males de caridad, la edición de material didáctico y la impartición de cursos formativos. Inclusive el fondo creado por la FAC por la amortización de los créditos de la construcción de viviendas se trasladó a Caritas. La FAC siguió construyendo viviendas hasta 1994, "pero son edificios que se edifican con el cuentagotas".

Por su parte, aunque el Faprode, la entidad financiera que no estaba legalmente controlada por la diócesis, persiste hasta nuestros días bajo el control indirecto de González Torres, ya no existe el sistema de swaps social, pues el fondo se transformó en una asociación de segundo piso que supervisa las tres residencias para adultos mayores y otras obras impulsadas inicialmente por la FAC. En 1994, Corripio pasó a retiro y González Torres consideró que tenía que dejar rápidamente la FAC y la diócesis. Seguramente influyó la llegada de Norberto Rivera, y la gran enemistad suscitada entre los sacerdotes cercanos a Corripio y el nuevo arzobispo aceleró el cierre de la FAC. ${ }^{32}$

${ }^{32}$ Terminada la etapa de reconstrucción, la Delegación Apostólica tomó la delantera al Arzobispado de México en las relaciones con el gobierno y logró consolidar un vínculo con el salinismo, que desembocó en la reforma constitucional de 1992. Todo esto redujo el margen de acción del Arzobispado de México. A continuación, con la llegada de Norberto Rivera se atrincheró el grupo de sacerdotes más cercanos a Corripio (in primis González Torres). 
Esta circunstancia no obsta al hecho de que la FAC se hubiera cerrado de todos modos, pues se habían terminado los grandes capitales captados y los grandes proyectos de viviendas y de generación de empleo. Los fondos que la FAC dejó a Caritas le permitieron a esta mantener su estructura dos años. En efecto, en la segunda mitad de la década de 1990 la estructura de Caritas es muy similar a la FAC: "se generó una Caritas para aguas de muchas organizaciones. En este sentido, esta es la estructura de FAC, aunque en la gestión de Caritas se crean otras cosas; por ejemplo, apoyo a los indígenas y salud comunitaria". ${ }^{33}$

Al final de esa década de 1990, el mecanismo de control de Caritas era bastante parecido al de la FAC, aunque con nuevos centros. En Caritas se establecieron divisiones operativas vinculadas a las parroquias (como los CEPAC de la FAC) y la oficina central de Caritas en el Arzobispado. Son como una división de coordinación de los centros, el equivalente a una oficina de segundo piso. ${ }^{34}$

\section{Conclusiones}

Escribe la revista Proceso en 1990: "Las acciones de la Iglesia no fueron neutrales. Su participación en la

${ }^{33}$ Entrevista con Manuel Zubillaga, Ciudad de México, 6 de octubre de 2015.

${ }^{34}$ Ibid. reconstrucción le hizo posible poner un pie en el terreno político, que iría llevando a un acercamiento cada vez mayor. [...] Quedó claro, en ese momento, el peso que la Iglesia tenía entre los damnificados y el terreno internacional". ${ }^{35} \mathrm{Mi}$ opinión es que la FAC desbloqueó mucho el trabajo político y social vinculado a la Iglesia católica. El conflicto religioso de la primera mitad del siglo XX produjo una Iglesia que no se introducía en los ámbitos que no fueran indispensables para su subsistencia.

Desde la II CELAM de Medellín (1968), las instituciones católicas que se dedicaron al trabajo social fueron sobre todo las comunidades eclesiásticas de base o, más en general, organizaciones vinculas a la teología de la liberación. En líneas generales, la Iglesia no se mezclaba en actividades que pudieran ser objeto de cuestionamientos, por su cercanía a medios considerados de izquierda. Con el sismo y la formación de la FAC, todo esto cambió repentinamente. La FAC era una institución vinculada al Arzobispado de México, representativa de la jerarquía.

Estos acontecimientos abrieron y ampliaron el margen de acción de la diócesis. Se derribaron obstáculos en la Iglesia institucional para una

${ }^{35}$ Proceso, "Obispos mexicanos piden donativos en Washington para intercambiarlos por deuda mexicana", 29 de enero de 1990, p. 14. 
acción social y política que más adelante desembocó en los cambios fundamentales del régimen salinista. El terremoto fue un movimiento no solo telúrico, sino que propició un acercamiento formal a la Iglesia católica de agrupaciones políticas y sociales que antes estaban distanciadas. La nueva situación generó fuertes críticas, sobre todo en la misma Iglesia, y no es sencillo determinar si la FAC era gobiernista (como decían sus críticos) o si impulsó al gobierno hacia un proyecto común (como dicen González Torres y Zubillaga).

Desde una perspectiva histórica, la FAC es relevante más que cuantitativamente (por las viviendas que construyó y el dinero que invirtió), como impulsora de un cambio y una apertura de la Iglesia católica hacia la sociedad y hacia la política. El cambio dependió en buena medida del contexto favorecido por Corripio, González Torres, Zubillaga y la propia emergencia del sismo. La fuerza y el impacto que tuvo la FAC en la Ciudad de México no se repitió.

La cercanía de la FAC con el gobierno federal y con las autoridades del Distrito Federal fue única. Después, por ejemplo, ha habido relaciones entre Andrés Manuel López Obrador y Norberto Rivera por la plaza Mariana, pero son tratos personales que no abarcan sectores sociales. A partir de la década de 1990, el contexto cambió y la acción de la Iglesia ya no tuvo la misma contundencia. El fenómeno social del terremoto propició, paradójicamente, una acción positiva, al impulsar a la Iglesia católica a adoptar una estructura conforme a las necesidades de los capitalinos: in natura veritas. 
CITAM Derechos Reservados.

La reproducción total o parcial de este artículo se podrá hacer si el ITAM otorga la autorización previamente por escrito. 